\title{
Young Language Learners' Collaborative Learning and Social Interaction as a Motivational Aspect of the iPad
}

\author{
http://dx.doi.org/10.3991/ijet.v10i2.4313 \\ Mona Alhinty \\ University of Sheffield, Sheffield, United Kingdom
}

\begin{abstract}
Second language (L2) motivation is of great importance for young foreign language learners, as it can both attract their interest towards learning the target language and improve their L2 achievements. Supporting students' need for relatedness (along with a need for competence and autonomy) is claimed to enhance behaviors that are selfmotivated and self-determined. The purpose of this study is to explore the affordances of tablet technologies, such as Apple iPads, for satisfying young language learners' need for relatedness, both in classroom collaborative learning and social interactions beyond the school settings. The key findings of this qualitative study suggest the iPad's potentiality for promoting L2 motivation through exploiting its affordances to enhance collaborative learning and social development.
\end{abstract}

Index Terms-iPad; collaborative learning; L2 motivation; Self-Determination Theory; relatedness; foreign language; children; social interaction; MALL

\section{INTRODUCTION}

In non-educational environments, mobile technologies have become increasingly ubiquitous and popular, particularly among the younger generation. Thus, students are already motivated towards their use, regardless of their functionality within a learning context [1]. Research on mobile learning has indicated that the utilization of mobile devices in education can positively enhance students' engagement, motivation and understanding of the subject, and encourage interaction and collaborative learning [2, 3]. A number of studies in mobile learning research have suggested a number of motivational aspects of mobile technologies relevant to learning. For example, based on earlier literature of mobile learning (ML), $[1,4]$ identify six factors that make mobile devices motivating, particularly in informal learning. These include: control over students' own goals; a sense of ownership, communication and collaborative learning; fun and entertainment; learning-in-context; and continuity between contexts afforded by the iPad's portability. Within the context of language learning, [5] also include the usefulness of such technologies for enhancing learners' interest and motivation; increasing their access to language resources; and encouraging extended interaction and feedback.

Although the findings of a number of studies in ML research suggest that mobile technologies can be motivating for learning, the focus on motivation in ML is still a relatively developing area [1], particularly in the language learning field. [6] highlights the need to research the motivational potential of mobile technologies for learning, as knowledge of their potential to learners is still very limited. More specifically, Self-Determination Theory (SDT), as a motivational theory, in Mobile-Assisted-LanguageLearning (MALL) is still an under-researched area. Therefore, this paper seeks to understand the use of iPad tablets within collaborative learning environments in the classroom (and informal social interactions outside the classroom), to satisfy the need for relatedness in young language learners that is necessary for motivating them to learn the English language.

\section{The NeEd for Relatedness IN MALl ConteXts}

Self-Determination Theory is one of the most influential cognitive theories of motivation [7]. It was first applied to second language (L2) learning by Noels et al. [8, 9] in order to examine the ways in which the "regulation of language learning becomes internalized into the learner's self-concept and how self-determined action brings about positive outcomes" [10, p. 143]. According to SDT, three fundamental needs must be taken into account to understand motivation: the need for autonomy (sense of volition); the need for competence (sense of accomplishment); and the need for relatedness (sense of connectedness). The satisfaction of these needs promotes increased self-determined and self-motivated behavior [11]. To cultivate and sustain intrinsic motivation (i.e., internal enjoyment of learning), and to ensure that extrinsic motivation (i.e., learning because of external pressure) is effectively internalized and accepted into the self, learners' desire for a sense of belonging and feelings of warmth and connectedness to other people (described in the SDT framework as a sense of 'relatedness') must be satisfied $[10,11]$. According to SDT, providing students with opportunities that satisfy their need to feel valued, secure and closely connected to significant others (such as teachers, parents, peer groups or society at large) encourages them to engage in activities perceived as uninteresting and fosters their intrinsic motivation to explore, learn, and accomplish.

[12] proposes that the need for relatedness in a technology-mediated language-learning context can be viewed from a socio-cultural perspective that emphasizes the important role of social interaction in facilitating and developing learning [13], as human beings use mediational tools (such as language, symbols and signs) to engage in conversation and negotiate meaning [14]. The concept that knowledge is 'mediated socially' [15, p.86] fits well with the nature of language learning, as stated by [16]: "second language learning is a social process in which 
language develops largely as a result of meaningful and motivated interaction with others" (p.14). [17] points out that motivation and collaboration are strongly associated: being involved in, and sharing activities with others is in itself motivating. Collaboration is considered "a motivated activity because it has a distinct, important emotional dimension' [1, p.254]. The reasons that make collaboration motivating, as noted by [17], are the 'shared meaning' constructed and developed by a pair, or a group, during their interaction in collaborative activities, alongside the idea that these shared experiences are unique to this specific pair or group. In recent years, researchers have paid increasing attention to the use of technologies as mediational tools and supportive media for L2 interaction and collaborative learning [18, 19]. Technologies such as computers, mobile devices, and more recently tablets, are increasingly viewed as potential platforms for social interaction and communication for educational purposes. [12] indicates that in language-learning environments, students' relatedness can be viewed in terms of their innate desire to be connected to their learning community in the classroom. However, in many EFL contexts, teacher-centered approaches are commonly used, particularly when there are large class sizes, leading to this interaction being typically teacher-controlled, as the teacher is the one who asks questions, corrects answers and provides feedback Although some teachers (depending on their teaching methods) may wish to encourage peer feedback, EFL students are therefore often not provided with sufficient opportunities to practice the target language in a collaborative manner. This can undermine their motivation and interest in learning the English language [20]. Benefiting from the mobility, instant accessibility and immediacy of information-sharing provided by mobile devices, face-to-face and online group activities can enhance collaborative learning by encouraging active and meaningful interaction and spontaneous communication between learners [19, 21, 22]. In relation to this, [21] makes the following observation:

M-learners can enjoy a high degree of collaboration by making rich connections to other people and resources mediated by a mobile device. This often-reported high level of networking creates shared, socially interactive environments so m-learners can readily communicate multi-modally with peers, teachers and other experts, and exchange information. (p. 10)

Mobile technologies with suitable integrated applications are an effective means of facilitating small-group collaborative learning activities that would otherwise be challenging to perform [23]. According to [22], even if the mobile nature of such activities is not salient: "the design of the learning activity is predicated on close interaction, conversation and decision-making between members of a group, which includes some physical movement and can be difficult to achieve with the use of fixed computers" ( $p$. 160). Furthermore, students may exploit the affordances of mobile technologies to produce collective digital outputs. Various applications of mobile devices have been informed by the social-constructivist learning paradigm. The capabilities and multi-functional characteristics of mobile devices provide a rich platform for designing social-constructivist learning scenarios. The relevance of mobile technologies for collaborative and socialconstructivist concepts has been considerably emphasized [20]. It is the inclusion of the social dimension and its support for co-present collaboration and interaction with others that ensures the social-constructivist approach is suitable for many mobile learning activities, including those related to language learning. [12] suggests that technologies that offer Web 2.0 applications (such as blogs and Wikis) can support language learners' need for relatedness. These social networks provide learning environments that can facilitate (and increase) language learners' interaction with their peer groups.

\section{STUDIES ON COLLABORATIVE LEARNING AND SOCIAL INTERACTIONS IN THE CONTEXT OFAN IPAD}

Tablet devices, as another form of mobile technology, may play a similar role in promoting students' co-present collaboration and interaction. However, research indicates that multi-touch tablets offer increased opportunities to support learners' collaborative learning. [24], for example, notes that the iPad's large screen allows 360-degree viewing, enabling a group of children to share its use, unlike desktop computers around which students must crowd to see the content. In addition, the iPad's portability and lightweight frame make it easy for the device to be carried, used collectively in various settings, and passed between users whenever needed.

Furthermore, [25] carried out an intervention with bilingual children to examine the impact of tablets (i.e. the Apple iPad) on language learning and literacy practices. The findings indicate that the portability and shared screens of tablets make them useful tools for communication and the sharing of information. The mobility of the tablets enables children and teachers to use the devices in different areas, which encourages various forms of collaborative work. Researchers also indicate that the iPad's shared screen and a suitable sound volume in the apps are necessary for encouraging the children's interaction. Additionally, they have indicated that the children's peer interaction was enhanced by the iPad's multi-touch screen, which not only enables single-user interaction but also enables a pair of children to jointly interact with an app. The study reported extensive peer support; children were helping each other whenever needed, whether in pair activities or in full group work. The portability of the tablet and its shared screen facilitated turn-taking and made it easy. Projecting the children's activities by connecting the tablet to a large display on wall was also reported to enhance the children's collaboration and the interaction between the child controlling the iPad and displaying the app and the rest of the group, who helped, or gave suggestions.

Similarly, [26] reported a study conducted with Freshman English classes. The data indicates the usefulness of the iPad's portability in enhancing students' collaboration while learning. The researchers point out that the tablet's large screen, high sound volume and light weight facilitated sharing the device between students and made it easy to pass it around between them. Furthermore, they found that the tablet's multi-functionality (such as video and audio recording, taking photographs, web searching and writing) encouraged creating faster, more appropriate and socially inclusive presentations in the classroom. The iPads portability features and the multi-touch screen motivated students to mutually create presentations and watch them, so making it suitable for collaborative learning.

In a further study conducted by [27], a number of iPad apps were found to be effective in supporting and enhanc- 
ing collaboration among younger students, as they allowed them to use the screen concurrently to draw and write, etc. They also observed that the children tended to work collaboratively in solving any problems they faced when using the iPad, discovering their own ways to navigate the device.

Furthermore, [28] carried out an intervention with primary school children, noting that they enjoyed sharing iPads in the classroom. The interviews conducted with the children and their families at the end of the first semester showed that some children were both pleased and proud to demonstrate their iPad's skills to their family members, enjoyed teaching their younger siblings ways to use easy apps, and were proud to use the tablet their parents were using. However, the collected data after the second semester revealed the children's dissatisfaction with being forced to share an iPad in the classroom and their preference for an individual tablet. The researchers point out that this change of children's attitude towards the iPad's collaborative approach may be a result of the diminishing of the tablet's novelty, and the teacher's insufficient designing of iPad's activities. Also [29] describe children's feelings of excitement and pride when sharing their iPads' digital productions with family members and the school community on schools' Twitter pages and YouTube channels.

Supporting such feelings of relatedness to significant others is essential to eliciting students' intrinsic motivation and ensuring the development and continuation of the learning process. However, though these empirical studies shed light on the social dimension of using the iPad for learning, the majority did not focus on examining the social context as a fundamental antecedent for motivation. Furthermore, there has been little research undertaken to examine young foreign language learners' use of tablets to support their need for relatedness and how this support can motivate them to learn the target language.

\section{THE RESEARCH DESIGN}

\section{A. Research question}

Based on Self-Determination Theory, the present study aims to examine the following question:

How can supporting the need for relatedness, through the use of iPad tablets by young language learners within collaborative classroom contexts and informal social interaction outside of classroom, enhance their motivation to learn the English language?

\section{B. Data collection Methods}

The study adopts an exploratory qualitative case study. During the two month study, a number of qualitative methods were used to collect data, including: classroom observation; focus group discussions after each class; post-intervention one-to-one semi-structured interviews; focused group discussions with the whole class; and blogging, using a child-friendly blog created by the researcher.

\section{Materials}

Since MALL is a relatively new field, it is essential to prepare, and offer, suitable language-learning environments [30]. This is highlighted by [31], who states, "the effective use of any tool in language learning requires the thoughtful application of second language pedagogy" (p.9). For the purpose of this study, iPad tablets were chosen for their unique characteristics as potential educational tools for children. Ten tablets were purchased and preloaded with a selection of educational apps, which were carefully selected by the researcher to blend in with their English syllabus.

\section{Participants}

Twenty primary school children participated in the study. They were aged between 9-10 years old, and learning the English language as beginners. Students were divided into pairs and were assigned an iPad to share during their English language classes (two English classes per week, each lasting 45-minutes). Students were encouraged to use a number of educational apps (both English-specific apps and open-ended generic apps) inside the classroom. In addition, students were encouraged to use the iPads at home on a daily basis to learn English and to connect to their class peers through a blog.

\section{E. Analysis and findings}

The current stage of the research reveals interesting patterns regarding young language learners' collaborative learning and social interaction as a potential motivational aspect of iPad use. The preliminary analysis of the data suggests that the iPad's affordances (such as portability, large-touch screen, variety of applications and multifunctionality) did indeed enhance children's collaborative learning in the classroom and supported their social interaction beyond the school context which thus increased their motivation to learn the target language.

During their shared use of an iPad, students were observed taking turns, passing the device, planning, discussing, negotiating, solving problems and helping each other. Although sharing the iPad imposed a number of challenges, students expressed a strong preference for sharing the iPad and found it fun and found this more motivating than working on it individually. For instance, when Sarah was asked about her opinion of sharing the iPad with her classmate, she said:

I prefer to use the iPad with my friend. I don't like to use it alone at home. When I want to play a two-player game I can't find someone to play with me... my brother is much younger than me.

Furthermore, students showed enjoyment and expressed feelings of excitement when they used the iPad to socially construct language materials. Empowered by the multifunctionality of the tablet and the powerful capabilities of some of its apps, students actively created their own digital works. These included carrying their iPads, moving around, taking photographs and recording their voices; creating animations; playing roles using digital characters; creating digital flashcards; drawing and coloring, all using the same device. For example, in every lesson, the children were enthusiastic about creating their visual digital alphabet sheets using Doodle Buddy, in which they have the option to use the iPad camera to take photographs, search for images using search engines, or to use one of the drawing apps to draw objects representing the letter they are studying. At the end of the project, they recorded their voices and added them to all the created sheets using another app (SonicPics) in order to form their audio-visual alphabet book. The class digital book was then shared with the rest of the class using the projector. This experience was evaluated as positive by the students, who were very excited to share their work with their classmates. 
I like it so much... the best thing is that it saves all our works as an English book, that we can turn its pages but here I can hear my voice and the voices of my friends... it saves all our efforts and everything we did from the beginning and shows it to us (Lena)

Encouraged by the portability of the iPad, students were assisting, scaffolding and evaluating each other's works. Alongside carrying the tablet and approaching the researcher when facing a difficulty, students would seek the assistance of their more capable peers. Children were observed carrying their iPads and going to other students when encountering a linguistic or technical issue, asking for help in, for example, checking a spelling of a word, and ways of resizing an image, fixing a sound problem or save an in-app recording.

Students reported that they regularly showed their parents, siblings and relatives the apps they were using in school. Many of them reported that they enjoyed teaching their younger siblings (and even the adult members of the family) how to create animations, mini-digital stories and educational games. The majority of the students expressed their enjoyment in creating professional animated films with their siblings or young relatives using creative apps (such as Toonastics), in which they created their own characters and settings and then recorded their own imaginative stories using the structures and vocabulary they had learnt in their English class. Additionally, they were able to save them and share them with others. Screencasting apps (such as Showme) were also regarded as enjoyable, and students felt proud as these enabled simultaneous recording of their productions and drawings while using the app, and also saving and sharing them with close friends. For instance, one of the students indicated how proud she was to show her family her personal digital flashcards:

When making a flashcard, I record the new word with my voice... when you show it to your family they feel proud of yourself... I feel I did something... So my family will be proud of me and they will know that I can make amazing things.., I choose images with beautiful colors and then I choose the words that we are learning so when they open the flashcard they are surprised to hear my voice. (Nora)

The children were excited about mobile blogging and found it a new and interesting experience. The main benefits of iPad blogging were seen to be meeting their classmates virtually, posting snapshots and images of their digital language productions, sharing discoveries of new educational apps, posting comments, enquiries and even greetings. Students indicated their preference for the synchronous mobile interactions, as they obtained instant answers or feedback from their peers and the researcher, which made them feel more connected to their language community of practice. However, many students reported some challenges that distracted them from their mobile blogging, including a heavy workload of homework and exams, parents restricting their use of the blog, and a weakness or disconnection of Wi-Fi coverage.

Although the portability and size of the iPad has enhanced students' collaborative learning and social development, students reported some challenges that occurred while using and sharing the iPad. These problems included: the family's perception of the iPad as a means of entertainment and thus interrupting the children's iPad learn- ing, in contrast to when they were using books; the family's perception of mobile class blogging as chatting and not learning; and deletion of educational apps by family members sharing the device. Furthermore, on a number of occasions some students complained that the partner with whom they shared the iPad was distracting them from their studies by going onto Youtube or saving preferred images through Google searching. A further issue was observed, and reported by students, concerning one of the pair dominating the use of the iPad, and disagreements on choices or in taking turns with the tasks.

The data, however, shows that the students managed to overcome such issues of dominance and disagreement by setting their own rules, such as deciding the roles of each member at the start of the task, and then exchanging these roles during the following activity.

She chose the bag she liked to take photo of while I wrote the word [bag], and she wrote the letter, then I took photo of the backpack I liked and she wrote the word and I wrote the letter... this way we feel more enthusiastic and we help each other in finishing our work. (Sarah)

Additionally, students reported that some apps (e.g. animation apps such as Puppet Pal2) enabled simultaneous audio recording or concurrent use of the touch screen. These enhanced their use of the multi-touch screen, in contrast to apps (e.g. Blackboard) that prevented joint use of the screen.

I like Doodle because it's easy and we never fight when using it... we can write with two or three fingers!! (Ameera)

Such apps were very popular with the students and thus were used not only for their productions, but also for gaming. This included Doodle Buddy, which was used extensively for playing guessing games, and number races.

\section{DisCUSSION AND CONCLUSION}

The key findings of this ongoing research indicate that the iPad can be used as a potential mediational tool for satisfying the needs of young students for relatedness in classroom collaborative learning, and also beyond the school context. This enhances their intrinsic motivation to learn the target language. Through the use of iPad and its educational applications, students were encouraged to learn English collaboratively. This included creating and constructing their digital language outputs with their peer group, scaffold and assist each other, along with sharing their iPad productions and discoveries with their friends, family and language learning community within the school.

The affordances of the iPad expanded the children's opportunities of feeling related, belonging and connected to significant others, thus enabling them become highly motivated to learn the language. These findings provided empirical support for the research enquiry of this study, which is consistent with earlier studies by $[10,11]$. The mobility of the tablets enhanced students' collaborative learning, which concurs with [19, 21]. Encouraged by their lightness and large screen, students were able to use their iPads in different locations in class. For example, during their use of English-specific apps, and some types of open-ended apps (e.g. animation screen-casting or drawing apps), many of the children tended to use their iPads on their desks, or in their labs. However, the mobility of the iPads was most exploited when students were 
using the iPad camera for completing their activities. Many of the pairs were observed carrying their devices and moving around the class hunting for suitable objects to film and use in their digital works. A pair could be heard laughing excitedly as they found an apple in a peer's lunchbox and were thus able to take photo of it to use it in their letter $A$ digital sheet. Another pair, who were assigned letter $E$ chose to take their iPad to the school kitchen in search of an egg to photograph, coming away happily with several pictures to use and share with friends. Such patterns of socially constructed activities were largely facilitated by the portability of the iPad and its inbuilt camera.

Additionally, alongside the multi-functionality of the iPad, the various ranges of open-ended applications with an integrated variety of capabilities enhance students' social development by encouraging their social construction of knowledge, which is consistent with studies [20, $25,26]$. Students may begin a task by planning their activity either in a group or in pairs, and then use a tablet (or other mobile technology) to collect or produce the required data in the classroom or outdoor settings. This may involve writing notes, drawing digital pictures, taking photos or recording audio and video clips. The learners' final productions and findings can be then shared and discussed, either in the classroom or virtually through blogs or school websites. For example, one app (Strip Designer) enabled students to take photographs, draw, write, type, and add stickers and speech balloons. This added enhanced excitement and enthusiasm to their shared interactive experience, and in turn motivated them to engage in language learning.

Furthermore, along with the portability of the iPad, the large multi-touch screen encouraged students' scaffolding, assistance and evaluation, as indicated in the study of [25]. Though the young participants owned and used iPad tablets and other computing devices at home, their level of technological competence varied. Hence, some students in the class were frequently observed carrying their iPads and going to the researcher, or their peers, seeking help with a technical issue. Scaffolding provided by an adult, or a more proficient peer, can help to maintain students within their zone of proximal development [13] and thus encourage their learning engagement, persistence and motivation.

In addition, the various capabilities, multi-modality and multi-functionalities of the tablets played a role in enhancing the students' sense of pride and self-efficacy when demonstrating and sharing their digital productions with significant others, such as teachers, peers, and family. This is confirmed by [28, 29]. Students frequently reported showing their family members their digital language output. They expressed feelings of pride and empowerment each time they shared with others their animated films, digital flashcards, comic strips, and audio recordings of their English chants, or their digital drawings representing the new letters and words they were studying. They were eager to show their creative works to impress those close to them and were thus happy to receive praise and compliments. According to SDT, supporting such feelings of connectedness and relatedness is a necessary condition for enhancing students' intrinsic motivation and facilitating their absorption of extrinsic motivation [23].
The interaction of the entire class was enhanced by projecting students' creations in class and blogging outside school hours. Although (due to technical and social challenges) students were less interactive in their blogging than had been expected, this new experience introduced them to a novel learning platform that extended the limited hours of their language classes, and enabled more asynchronous and synchronous interactions with their peers, as indicated in the literature [12]. This further encouraged their use of iPads for language learning through sharing their new found apps and works with their peer group. Many students who had open access to the Internet were consistently checking the blog for comments on their posts or for their peers' posts, even if they were visiting or leaving town at the weekend. These findings are confirmed by [33] who conducted a study to explore the use of mobile technologies for a collaborative museum activity. Students were asked to work in pairs to produce a video blog based on their experiences in the museum. This socially-constructed activity enhanced the student's collaboration and extended their face-to face and blogbased interaction.

The challenges students reported when sharing the iPad (such as the dominance by one student of the device) is confirmed in the earlier research. However, this did not undermine students' motivation to use the iPad for learning the target language. At the beginning of the project, the students were introduced to, and familiarized with, the rules of using the iPads in the classroom, including respecting taking turns. Hence students' awareness of this rule, as well as the researcher's monitoring, played a role in minimizing its effects. Furthermore, environmental support is very important for encouraging self-motivated and self-determined behaviors. According to [24] "without a proper learning environment, management and facilitation, the device's potential may not be realized"' [p.87]. Therefore, designing meaningful MALL activities that work towards enhancing students' collaboration and interaction was significant in promoting students' intrinsic motivation. Before undertaking the intervention, the researcher designed every iPad lesson in accordance with the English syllabus of the $4^{\text {th }}$ grade primary school class. Planning iPad language learning activities was time consuming, as it included selecting and previewing appropriate educational apps from an extensive range of apps available in the App Store, and designing languagelearning content that was able to utilize the iPad's unique features. However, this step was crucial to ensure that the iPad use would "enhance curricular goals and support student learning, [relatedness and in turn their motivation] in new and transformative ways" [27].

The emerging evidence suggests considerable potential for iPad utilization to support students' need for relatedness, which is essential for enhancing their intrinsic motivation and facilitating the internalization of extrinsic motivation. Further elaboration of these findings is expected to offer language teachers, MALL researchers and designers, a clearer idea of the affordances of the iPad, along with ways to apply this knowledge for enhancing students' classroom collaborative learning and social interactions beyond the school, which can, in turn, motivate them to learn the target language. 


\section{REFERENCES}

[1] A. Jones, K. Issroff, E. Scanlon, G. Clough, and P. Mcandrew, "Using mobile devices for learning in informal settings: is it motivating?" in IADIS International Conference Mobile Learning, 2006, pp. 251-255.

[2] A. Kukulska-Hulme. "Mobile language learning now and in the future," in Vision to practice: language learning and IT. Sweden: Swedish Net University, 2006, pp. 295-310.

[3] P. Twining, D. Evans, D. Cook, J. Ralston, I. Selwood, et al. "Tablet PCs in schools: Case study report: A report for Becta by the Open University." Coventry, UK: Becta, 2005.

[4] A. Jones and K. Issroff, "Motivation and mobile devices: exploring the role of appropriation and coping strategies," Alt-J, Res. Learn. Technol., vol. 15, no. 3, pp. 247-258, Sep. 2007. http://dx.doi.org/10.1080/09687760701673675

[5] E. M. Golonka, A. R. Bowles, V. M. Frank, D. L. Richardson, and S. Freynik, "Technologies for foreign language learning: a review of technology types and their effectiveness," Comput. Assist. Lang. Learn., vol. 27, no. 1, pp. 70-105, Feb. 2014. http://dx.doi.org/10.1080/09588221.2012.700315

[6] C. Tran, M. Warschauer and A. Conley, "Tapping the motivational potential of mobile handhelds: Defining the research agenda. In G. Trentin \& M. Repetto (Eds.), Using network and mobile technologies to bridge formal and informal learning. Oxford, UK: Chandos Publishing, 2013, pp. 1-29. http://dx.doi.org/10.1016/B978-1-84334-699-9.50001-X

[7] Dörnyei, Z, The Psychology of Second Language Acquisition. Oxford: Oxford University Press. 2009.

[8] K. A. Noels, R. Clément and L. G. Pelletier, "Perceptions of teacher communicative style and students' intrinsic and extrinsic motivation', Modern Lang. Journal, vol. 83, pp. 23-34. 1999. http://dx.doi.org/10.1111/0026-7902.00003

[9] K. A. Noels, L. Pelletier, R. Clément and R. Vallerand, "Why are you learning a second language? Motivational orientations and Self-determination theory'. Lang. Learn., vol. 50, pp. 57-85. 2000. http://dx.doi.org/10.1111/0023-8333.00111

[10] R. Comanaru and K.A. Noels, "Self-Determination, motivation, and the learning of Chinese as a heritage language," Can. Mod. Lang. Rev. La Rev. Can. des langues vivantes, vol. 66, no. 1, pp. 131-158, Sep. 2009.

[11] E. L. Deci and R. M. Ryan, "The 'What' and 'Why' of goal pursuits: Human needs and the Self-Determination of behavior," Psychol. Inq., vol. 11, no. 4, pp. 227-268, Oct. 2000. http://dx.doi.org/10.1207/S15327965PLI1104_01

[12] A. Alm-Lequeux, "CALL for autonomy, competence and relatedness: motivating language learning environments in Web 2.0," JALT CALL J., vol. 2, no. 3, pp. 29-38, 2006.

[13] L.S. Vygotsky, Mind in society: The development of higher psychological processes. Cambridge: Harvard University Press. 1978.

[14] J. Wertsch, Voices of the mind: a socio-cultural approach to mediated action. Cambridge, Mass.: Harvard University Press. 1991

[15] U. Felix, "E-learning pedagogy in the third millennium: the need for combining social and cognitive constructivist approaches". ReCALL. vol. 17 , no. 2, pp. 85-100, 2005http://dx.doi.org/10.1017/S0958344005000716

[16] C. Goldenberg, "Unlocking the Research on English Learners," Am. Educ., vol. 37, no. 2, pp. 4-11, 2013.

[17] C. K. Crook, "Motivation and the ecology of collaborative learning', in Rethinking collaborative learning R. Joiner, K. Littleton, D. Faulkner \& D. Miell, Eds. London, Free Association Press, 2000, pp. 161-178.

[18] D. Laurillard, "Pedagogical forms for mobile learning: framing research questions," in Mobile learning: towards a research agenda, no. 2007, N. Pachler, Ed. London WLE Centre, IoE, 2007, pp. $153-175$.
[19] M. Sharples, J. Taylor and G. Vavoula, "A theory of learning for the mobile age," in The Sage handbook of e-learning research R. Andrews \& C. Haythornth-Waite, Eds., London: Sage, 2007, pp. 221-245.

[20] Y.-J., Lan, Y.-T, Sung and K.-E Chang, "From particular to popular: Facilitating EFL reading through mobile-supported cooperation”. Language Learning \& Technology, vol. 17, no.3, pp. 2338, October, 2013

[21] M. Kearney, S. Schuck, K. Burden, and P. Aubusson, "Viewing mobile learning from a pedagogical perspective," Res. Learn. Technol., vol. 20, no. 14406, pp. 1-17, Feb. 2012. http://dx.doi.org/10.3402/rlt.v20i0.14406

[22] A. Kukulska-Hulme and M. Sharples, M. Milard, I. ArnedilloSánchez, and G. Vavoula, "Innovation in mobile learning: a European perspective," Int. J. Mob. Blended Learn., vol. 1, no. 1, pp. 13-35, 2009. http://dx.doi.org/10.4018/jmbl.2009010102

[23] G. Zurita and M. Nussbaum, "Computer supported collaborative learning using wirelessly interconnected handheld computers," Comput. Educ., vol. 42, no. 3, pp. 289-314, Apr. 2004. http://dx.doi.org/10.1016/j.compedu.2003.08.005

[24] S. Henderson and J. Yeow, "iPad in education: A case study of iPad adoption and use in a primary school," in 2012 45th Hawaii International Conference on System Sciences, 2012, pp. 78-87.

[25] M. Sandvik, O. Smørdal, and S. Østerud, "Exploring iPads in practitioners' repertoires for language learning and literacy practices in kindergarten," Nord. J. Digit. Lit., vol. 7, no. 3, pp. 204 220, 2012.

[26] M. Brown, J. Castellano, E. Hughes, and A. Worth, "Integration of iPads into a Japanese university English language curriculum," JALT CALL J., vol. 8, no. 3, pp. 197-209, 2012.

[27] A. Hutchison, B. Beschorner, and D. Schmidt-Crawford, "Exploring the use of the iPad for literacy learning," Read. Teach., vol. 66 , no. 1, pp. 15-23, Sep. 2012. p.23

[28] A. Gasparini and A. Culen, "Acceptance factors: An iPad in classroom ecology," in e-Learning and e-Technologies in Education (ICEEE), 2012, pp. 140-145.

[29] J. Lynch and T. Redpath, "'Smart' technologies in early years literacy education: A meta-narrative of paradigmatic tensions in iPad use in an Australian preparatory classroom," J. Early Child. Lit. (ecl)., pp. 1-28, Aug. 2012.

[30] J. Colpaert, "From courseware to coursewear?" Comput. Assist. Lang. Learn., vol. 17, no.3-4, pp. 261-266, 2004. http://dx.doi.org/10.1080/0958822042000319575

[31] G. Chinnery, "Emerging technologies. Going to the mall: mobile assisted language learning," Lang. Learn. Technol., vol. 10, no. 1, pp. 9-16, 2006.

[32] E. L. Deci and R. M. Ryan, Intrinsic motivation and selfdetermination in human behavior. New York: Plenum, 1985. http://dx.doi.org/10.1007/978-1-4899-2271-7

[33] J. Cook, "Mobile phones as mediating tools within augmented contexts for development', in Education in the wild: contextual and location-based mobile learning in action, ed. E. Brown, Learning Sciences Research Institute, University of Nottingham, UK, pp. 23-26, 2010. http://dx.doi.org/10.4018/jmbl.2010070101

\section{AUTHORS}

Mona Alhinty is with School of Education, University of Sheffield, Sheffield, United Kingdom (e-mail: m.alhinty@sheffield.ac.uk).

This article is an extended and modified version of a paper presented at the the Interactive Mobile and Computer Aided Learning (IMCL2014), held in November 2014, in Thessaloniki, Greece. Submitted 09 December 2014. Published as resubmitted by the authors 24 March 2015. 